\title{
Sobre o caráter ontológico da ciência: possíveis contribuições de Nicolai Hartmann para um problema do realismo especulativo
}

\author{
On the Ontological Character of Science: Possible Contributions of \\ Nicolai Hartmann to a Problem of Speculative Realism
}

\author{
Eduardo Nasser \\ e.nasser@ufabc.edu.br \\ (Universidade Federal do ABC, São Paulo, Brasil)
}

\begin{abstract}
Resumo: Quentin Meillassoux, um dos nomes mais promissores do realismo especulativo, tendência intelectual de nosso tempo que constitui opção ao legado $\mathrm{da}$ filosofia moderna, entende que o correlacionismo (Corrélationisme) só poderá ser desestimulado quando o problema da ancestralidade for seriamente enfrentado, e o prestígio ontológico do discurso matemático, o idioma da ciência, for recuperado. No século passado, Nicolai Hartmann propôs algo similar ao apontar para o enfraquecimento do correlativismo (Korrelativismus) ocasionado pela atitude científica. Todavia, diferentemente de Meillassoux, Hartmann entende que 0 valor da ciência para a ontologia não está na aptidão de matematizar o discurso, mas na ampliação da intuitividade e no desvelamento das categorias.
\end{abstract}

Palavras-chave: ciência; correlativismo; realismo especulativo; ontologia.

\begin{abstract}
Quentin Meillassoux, one of the most promising names of the speculative realism, intellectual tendency of our time that characterizes an option to the legacy of modern philosophy, establishes that the correlationism (Corrélationisme) can only be discouraged when the problem of ancestrality is seriously confronted and the ontological prestige of the mathematical discourse, science's idiom, is recovered. In the past century, Nicolai Hartmann proposed something similar, pointing to a weakening of correlativism (Korrelativismus) caused by the scientific attitude. However, differently from Meillassoux, Hartmann understands that the value of science to ontology does not lie in the aptitude of mathematizing discourse, but in the amplification of intuitivity and unveiling of categories.
\end{abstract}

Keywords: science; correlativism; speculative realism; mathematics; ontology.

DOI: http://dx.doi.org/10.11606/issn.2318-9800.v23i2p67-79

\section{Introdução}

Nossa atualidade testemunha o surgimento de uma promissora agitação intelectual que vem sendo chamada de realismo especulativo. Reunindo jovens filósofos, como Graham Harman, Quentin Meillassoux, Ray Brassier, Ian Hamilton Grant, o realismo especulativo - ou o "novo realismo", conforme Ferraris - ganha estatuto de movimento no dia 27 de abril de 2007, por ocasião do evento realizado na University of London ("Speculative Realism: A One-Day Workshop”) (Bryant, Srnicek, 
Harman, 2010, p. 2). Não obstante previstas diferenças, ${ }^{1}$ há o consenso unificador de que é preciso ir além da filosofia moderna - e também da pós-moderna ${ }^{2}$-, norteada por teses correlacionistas e/ou construtivistas.

Quentin Meillassoux aparece como uma das figuras proeminentes dessa nova onda filosófica, e a publicação de sua obra Après la finitude, de 2006, foi vista como um marco na consolidação do realismo especulativo. Nesse livro, Meillassoux identifica o pendor ocioso da filosofia a partir de Kant, que deixa de ousar interrogar as coisas mesmas. O realismo enquanto posição filosófica é rejeitado, dando lugar à convicção de que o conhecimento está encerrado numa perspectiva correlacionista, que pode ser fraca ou forte, a depender de sua intensidade. Correlação expressa o entrelaçamento pensamento e ser, cujos principais polos de referência, durante o século XX, foram a consciência (fenomenologia) e a linguagem (filosofia analítica). Dessa forma, o "grande fora" (Grand Dehors), indiferente a nós, e que existia em si, o fora dos pensadores pré-críticos, é suprimido (Meillassoux, 2006, p. 17 - 22).

Para Meillassoux, é a ciência, e não a filosofia, que enseja subsídios para o rompimento com o correlacionismo. Todas as ramificações filosóficas após Kant nada fizeram para subverter esse quadro, mesmo aquelas conhecidas por empreenderem críticas do sujeito (Nietzsche e Heidegger). Inversamente, os enunciados propalados por certas frentes da ciência sobre acontecimentos anteriores à vida e consciência - astrofísicos, geólogos e paleontólogos que investigam "a idade do universo, a data da formação da Terra, a data de surgimento de uma espécie anterior ao homem, a data de surgimento do homem mesmo" (idem, p. 25) - criam um embaraço de graves consequências para o correlacionismo. Enquanto a ciência, bem como o sensocomum, não contesta o valor realista desses enunciados, os filósofos submetem o conteúdo produzido por esses campos da ciência a estratagemas correlacionistas, como se os objetos investigados não existissem senão em relação ao homem. Tratase da convicção na intransponibilidade dos vínculos pensamento - ser / homem tempo que invalida a abordagem cronológica em beneficio da abordagem lógica. Os resultados são desastrosos, porquanto o discurso filosófico faz crer que nenhum dos eventos retratados tenha de fato acontecido em sua anterioridade cronológica ao homem. 0 problema da ancestralidade termina por revelar que o correlacionismo, reverenciado pela filosofia desde a modernidade, perpetua a antiquíssima infâmia de teses filosóficas entre cientistas, assim como reforça a indesejada proximidade com tendências obscurantistas, como o criacionismo. Por essa razão que Meillassoux roga

\footnotetext{
1 Graham Harman elenca as diferenças mais insinuantes: Brassier seria um reducionista, Hamilton um dinamista, Harman um fenomenólogo, e Meillassoux o único que se opõe radicalmente ao conceito de causalidade. Cf. Harman, 2007, p. 369.

2 Esse é um encaminhamento explorado por Ferraris, que aborda a pós-modernidade enquanto uma radicalização do kantismo, pois, neste momento, teses construtivistas confundem o epistemológico com o ontológico. Cf. Ferraris, 2014, p. 27.
} 
Sobre o caráter ontológico da ciência: possíveis contribuições de Nicolai Hartmann ...

ser necessário adentrar no caminho aberto pela ciência com o propósito de fazer com que o pensamento reencontre o absoluto.

Pensar a ancestralidade é pensar um mundo sem pensamento - um mundo sem dação do mundo. Nós temos então a obrigação de romper com o requisito ontológico dos modernos em que ser é ser correlato. Devemos, ao contrário, tentar compreender como o pensamento pode aceder ao não-correlato - a um mundo capaz de subsistir sem ser dado. Logo, dizer isso, é também dizer que devemos apreender como o pensamento pode aceder ao absoluto: a um ser desatado (sentido primeiro de absolutus), separado do pensamento, que se oferece a nós como não-relativo a nós capaz de existir quer existamos ou não. Mas eis aqui uma consequência notável: pensar a ancestralidade impõe, digamos, a renovação com o pensamento do absoluto; logo, através da ancestralidade, é o discurso mesmo da ciência experimental que tentamos compreender e legitimar - e, assim, deve-se dizer que longe de nos levar a renunciar a uma filosofia que pretende descobrir por seus próprios meios uma verdade absoluta, longe, portanto, como querem os diversos positivismos, de nos fazer renunciar à busca por um absoluto, a ciência impele-nos a descobrir a fonte de sua própria absolutidade. Pois se eu não posso nada pensar do absoluto, não posso dar sentido ao ancestral - e, por conseguinte, eu não posso dar sentido à ciência que permite o conhecimento (idem, p. 51).

A legitimidade de um discurso dia-crônico, decorrente do problema da ancestralidade, evidencia o potencial ontológico do discurso científico, cuja forma é a matemática. "Por meio da ancestralidade, o que está em jogo aqui é especialmente o que caracteriza esse discurso: sua forma matemática" (idem, p. 37). A grande virtude das ciências - sobretudo desde Galileu - foi utilizar a matemática como genuína linguagem da realidade que não se presta aos prejuízos correlacionistas. A matemática seria dotada da capacidade de explicitar as qualidades primárias, as propriedades dos objetos. "Tudo do objeto que pode ser formulado em termos matemáticos faz sentido ser pensado como propriedade do objeto em si" (idem, p. 15). Importante reparar que o idioma matemático da ciência não proporciona uma transição substancial; não se trata de fazer da matemática um veículo para um outro mundo, aos moldes platônicos. Ademais, Meillassoux, como Badiou antes dele, se apropria da teoria dos conjuntos de Cantor, que atribui atualidade ao infinito, com o propósito de alicercear a tese sobre a primazia ontológica do contingente. Não obstante esse rompimento com a metafísica dogmática, através da mobilização teorética da matemática executada pela ciência é admissível voltar a interpelar um absoluto.

O realismo especulativo impulsiona uma profunda revisão dos hábitos aferrados na produção intelectual dos filósofos de nosso tempo, criando uma atmosfera inegavelmente fecunda para um abandono mais decidido das heranças deixadas pela filosofia moderna. Porém existem algumas dificuldades ligadas a esse incipiente projeto, em especial no que diz respeito à crônica apresentada. Seria preciso reconhecer que, nos séculos XIX e XX, houve uma iniciativa notadamente semelhante, em contextos intelectuais diversos. Nomes ligados à fenomenologia e filosofia analítica 
insurgem-se contra o influxo idealista/psicologista, apregoando a necessidade de recuperar a metafísica e ontologia - um tipo de narrativa, portanto, inconciliável com aquela proposta por Meillassoux. Para muitos dos primeiros fenomenólogos alemães, a fenomenologia não se limitava a um exame das estruturas essenciais da consciência, como para Husserl após o primeiro volume da Investigação lógica, mas a um método intuitivo que almeja reaver as essências em geral, favorecendo, no limite, o surgimento de uma "nova escolástica". As incompatibilidades entre as concepções de fenomenologia de Husserl e dos seus discípulos, participantes dos círculos fenomenológicos de Munique e Göttingen, é manifesta, intensificando-se após a publicação do Ideias. Essas divergências são, em larga medida, consequências da posição que a fenomenologia deveria assumir perante a ontologia e metafísica (Spiegelberg, 1965, p. 168 - 173; Avé-Lallemant, 1975, p. 19 - 38). ${ }^{3}$ No contexto da filosofia analítica, a mobilização contra a metafísica prepondera somente nas décadas de 1930-50; os primeiros "analíticos", como Bolzano, Frege, Russell e Moore, estão comprometidos com algum tipo de realismo. De resto, metafísica e ontologia reaparece no âmbito da filosofia analítica com Quine e Strawson (Simons, 2013, p. 709 - 728). Mas o meu objetivo neste artigo não é o de tão somente propor reparos eruditos. Penso, antes, que o reconhecimento deste antecedente pode fortalecer a tarefa que ora se coloca para os novos realistas.

Dentre os filósofos que anteveem muitos dos desafios do realismo especulativo, há de se destacar o nome de Nicolai Hartmann. A correspondência entre a recuperação da metafísica e ontologia vislumbrada por Hartmann no século passado com os intentos do realismo especulativo em nossa atualidade foi identificada por Keith Peterson; os seus trabalhos notabilizam-se por estarem fazendo do pensamento hartmanniano uma profícua fonte para as metas do novo movimento (Peterson, 2016, p. 125 - 140; Peterson, 2017, p. 161 - 174). Pretendo adentrar pela mesma trilha a fim de abordar um tópico ainda inexplorado. 0 meu intuito é mostrar que Hartmann elaborou considerações sobre os benefícios da ciência para o resgate da ontologia, assim como Meillassoux, mas com acréscimos assaz importantes. Pois a vocação ontológica da ciência deixa de estar associada à capacidade de formular a matematização do discurso.

3 Ainda sobre essas diferenças, tome-se a seguinte declaração de Scheler: "Em sua última obra sobre Ideias, etc., Husserl aproxima-se consideravelmente do idealismo epistemológico (erkenntnistheoretischen Idealismus) de Berkeley e Kant, assim como da doutrina do eu de Natorp, e ele entende a fenomenologia como não sendo senão doutrina das essências das estruturas da consciência; mas, ao mesmo tempo, ele faz, como Kant, das estruturas da consciência pressupostos dos objetos da experiência mesma. Assim, para ele as leis da experiência do objeto tornam-se, ao mesmo tempo, as leis dos objetos de toda experiência possível ("virada copernicana" de Kant). Essa reviravolta peculiar de Husserl, segundo a qual uma consciência absoluta seria mantida mesmo quando todas as coisas fossem anuladas, foi rejeitada por quase todos os pesquisadores que ele inspirou e, ao mesmo tempo, é um grande obstáculo à construção de uma metafísica com base teórica nas essências" (Scheler, 1973, p. 311). 
Sobre o caráter ontológico da ciência: possíveis contribuições de Nicolai Hartmann ...

\section{Ontologia crítica}

Hartmann atesta que o interesse pela ontologia, que vai de par com as expectativas por uma renovação da metafísica, é uma vigorosa propensão de seu tempo. Nomes como Conrad-Martius, Günther Jacoby, Meinong, Scheler, Heidegger, contribuem para o amadurecimento dessa tendência, que, por fim, marca também o enfraquecimento dos pontos de vista neokantiano, positivista e psicologista. Hartmann insere-se nesse próspero cenário, indicando que seu engajamento com a recuperação da metafísica/ontologia não encontra acolhida no projeto de uma defesa da tradição (Jacoby) e tampouco em sua destruição (Heidegger). Mais inclinado a uma posição intermediária, manifesta afinidade com as obras de Hans Pichler (Über die Erkennbarkeit der Gegenstände e Über Christian Wolffs Ontologie), que teve o "grande mérito de ter sido o único a ter encontrado verdadeiramente o problema do ser" (Hartmann, 1965, p. VIII). Pichler foi particularmente importante por ter demonstrado a atualidade da ontologia de Christian Wolff - vista, então, pelo prisma da teoria do objeto de Meinong -, mas também por ter assinalado os impasses do procedimento dedutivista da ontologia wolffiana, que espera retirar princípios ontológicos de princípios lógicos (lei da não-contradição) (idem, p. 31 e 32; D’Anna, 2011, p. 266 e 267). A admissão de obstáculos inseparáveis da antiga metafísica especulativa delineia a ontologia crítica, que, auxiliada pelas reformas realizadas por Kant, espera "recuperar a antiga ontologia em seus problemas constitutivos e, ao mesmo tempo, deles se distanciar" (Hartmann, 1965, p. XI). Propor "retornar à metafísica" não significa "necessariamente um retorno à filosofia pré-kantiana (...) A tese de Kant: não há metafísica sem crítica, continua sendo efetiva" (Hartmann, 1921, p. 5).

O campo mais vulnerável à crítica, de onde emana o desprestígio logrado pela metafísica após Kant, é o campo da metaphysica specialis, puramente especulativo, cujos objetos de investigação - Deus, alma, totalidade do mundo - encontram-se fora de todo conhecimento possível. Como esses objetos adquirem estatuto de irracionais, no sentido de não poderem ser conhecidos pela apreensão (Begreifen), parece, então, que todos os problemas metafísicos são irrelevantes. Porém a existência mesma dos problemas alude à possibilidade de conhecer. Pautando-se neste argumento, Hartmann enxerga na ontologia algum índice da racionalidade (o campo da metaphysica generalis), o que termina por legitimar a metafísica, mesmo que a ontologia seja o ramo menos metafísico da metafísica. "O elemento ontológico das questões metafísicas fundamentais em todos os domínios de investigação mostrou-se como o lado manejável e passível de ser estudado" (Hartmann, 1965, p. 28). Essa asserção decorre do reconhecimento de que há algo do ser acessível na experiência e, assim, ao conhecimento. Malgrado o ser enquanto ser não se mostrar integralmente, 
sendo, portanto, um tópico parcialmente irracional, pode-se descobrir algo do ser junto ao ente. A nova ontologia aborda o ente real no vir-a-ser que "surge e deixa de ser", circunscrevendo a tarefa ontológica a uma análise modal do ser e da doutrina das categorias (Hartmann, 1958a, p. 334 e 335). Não o "ente exemplar”, como para Heidegger em Ser e Tempo, ${ }^{4}$ mas o ente enquanto ente (Seiende als Seiendes como

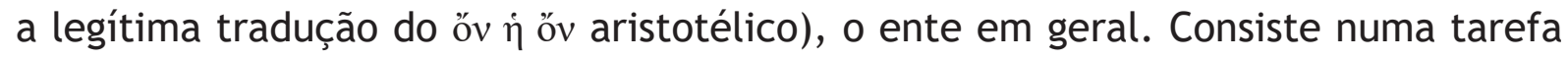
preparatória separar ser e ente, ơv e cĩval, ens e esse, confundido pelos antigos, fonte do equívoco que provocou particularizações do ser, quer como substância, essência ou incondicionado; mas "na prática é impossível tratar o ser (Sein) sem investigar o ente (Seiende)" (Hartmann, 1965, p. 38). O ser só pode ser acessado decorrido um processo. Isso explica a impossibilidade de a ontologia ser philosophia prima num nível epistêmico, devendo ser antes entendida como philosophia ultima.

\section{Correlativismo e o transobjetivo}

Retomar a ontologia, mesmo que criticamente, supõe ir contra o legado deixado pela filosofia moderna, que fez da ontologia um tópico obsoleto. É um direcionamento que adultera o desfecho da filosofia crítica de Kant - que na verdade almeja viabilizar a metafísica pela primeira vez -, restringindo o empreendimento filosófico à teoria do conhecimento. Após Kant, diversos tipos de teses psicologistas e logicistas (as duas grandes frentes do neokantismo) omitem a fonte metafísica do conhecimento; o conhecimento passa a ser visto como atividade eminentemente reflexiva e produtiva do sujeito ou do pensamento. Não que o problema do conhecimento em geral não acomode preocupações psicológicas e lógicas; mas são aspectos não-metafísicos do conhecimento que concorrem com aspectos metafísicos (Hartmann, 1921, p. 12 e 13). Ocultar a metafísica do conhecimento suscita a decadência do problema do conhecimento.

Para Hartmann, esse fenômeno historicamente situado é oriundo de um problema mais antigo, culturalmente disseminado, que remete ao "argumento correlativista (Korrelativistische)". Esse argumento determina que “não há objeto

$4 \mathrm{Em} \mathrm{Ser} \mathrm{e} \mathrm{tempo,} \mathrm{a} \mathrm{pergunta} \mathrm{pelo} \mathrm{sentido} \mathrm{do} \mathrm{ser} \mathrm{é} \mathrm{mediata} \mathrm{em} \mathrm{virtude} \mathrm{da} \mathrm{estrutura} \mathrm{mesma} \mathrm{do}$ perguntar, que implica um desvio (Befragte), e pelo "perguntar buscar o ente em seu Dass-sein e Sosein". Perscruta-se não diretamente o ser, mas o ente, que se encontra junto ao ser. Esse ente é o Dasein, ente exemplar para quem o próprio ser se torna um problema. Cf. Heidegger, 2006, p. 5 - 8. Embora essa articulação seja semelhante àquela concebida por Hartmann, existem diferenças significativas. Hartmann almeja ultrapassar a perspectiva transcendental de Heidegger, rejeitando qualquer tipo de proximidade com variações da filosofia do sujeito. Para Hartmann, Heidegger seria implicitamente um idealista; a pergunta pelo sentido do ser aponta para isso. Pois o ser mesmo não possui sentido; sentido é algo para o homem. Em outras palavras, a pergunta pelo sentido do ser invalida a questão pelo ser. Hartmann entende ser preciso realizar uma nova virada copernicana em que o homem fique situado ao redor do ser, algo que Heidegger não conseguiu admitir. Cf. Hartmann, 1965, p. 40 - 42. Para uma visão mais abrangente da tensa relação entre Hartmann e Heidegger, cf. Kluck, 2012, p. 195 - 218. 
do conhecimento sem sujeito do conhecimento" (Hartmann, 1965, p. 14). 0 conceito convencional de objeto, expresso pelas palavras Objectum e Gegenstand, alberga a proposta seminal do argumento em que se está sempre "diante de alguém". A rigor, a palavra Gegenstand engloba uma gama mais rica de significados - o conhecido (objectum), o que será conhecido (objiciendum), o desconhecido (transobjetivo), e o que não pode ser conhecido (irracional / transinteligível). Porém a correlação subjectif e objectif oblitera esse quadro polissêmico, fazendo com que objeto não seja senão uma imagem imanente produzida pelo conhecimento (Hartmann, 1921, p. 69 - 72).

O caráter legítimo do conhecimento coloca em evidência que o argumento correlativista é um pseudoargumento. Pois estima algo que não é realmente demonstrado. Um exame mais detalhado da natureza mesma do conhecimento revela que o correlativismo é posterior a uma ação refletida que imprime um recorte (sujeito-objeto) na dimensão mais vasta, transobjetiva, do ente.

Todo ente (Seiende) pode, sem dúvida, converter-se em objeto - ao menos em princípio, pois não se opõe à objetivação -; mas isso não quer dizer que tenha que se converter em objeto necessariamente, e tampouco que já seja um objeto (Gegenstand). É um erro pensar que todo ente é objeto e que somente o que é objeto possui caráter de ser (Sein). 0 mundo entendido como conjunto dos entes é, sem dúvida, só parcialmente objeto do conhecimento, talvez em sua menor parte. É o que ensina de forma impressionante o incessante descobrimento de domínios dos objetos no progresso do conhecimento (Hartmann, 1965, p. 17).

O conhecimento, quando sujeitado ao temperamento correlativista, perde seu traço mais originário e legítimo, em que conhecer não é criar ou imaginar, mas apreender o ente. "Conhecer não é criar, produzir, fazer nascer um objeto, como quis nos ensinar o idealismo antigo e moderno, mas apreender algo que existe antes de todo conhecimento e independente dele" (Hartmann, 1921, p. 1). Com essa revelação, é preciso admitir uma fragmentação qualitativa na concepção de conhecimento, respectivamente quando em relação reflexiva ao objeto e intuitiva ao ente.

\section{Atitude científica e ontologia}

O desencaminho epistemológico correlativista exprime um tipo determinado de atitude: a atitude reflexiva (intentio obliqua). Essa atitude, preponderante nos domínios da teoria do conhecimento, psicologia e lógica, ocasiona um desvio intuitivo, uma vez que o olhar deixa de se dirigir ao ente. 0 conhecimento legítimo, diferentemente, prospera quando resguardado por uma atitude natural (intentio recta) que mira o ente enquanto ente. Portanto, para cada tipo de conhecimento há um tipo de atitude correspondente. 


\begin{tabular}{|c|c|c|c|}
\hline $\begin{array}{c}\text { Conhecimento } \\
\text { legítimo } \\
\text { (apreensivo/receptivo) }\end{array}$ & $\begin{array}{l}\text { Atitude natural } \\
\text { (intentio recta) }\end{array}$ & $\begin{array}{l}\text { Conhecimento ilegítimo } \\
\text { (construtivo/correlativista) }\end{array}$ & $\begin{array}{c}\text { Atitude reflexiva } \\
\text { (intentio } \\
\text { obliqua) }\end{array}$ \\
\hline \multicolumn{2}{|c|}{ Ente (Seiende) } & \multicolumn{2}{|c|}{ Objeto (Gegenstand / Objectum) } \\
\hline
\end{tabular}

É a atitude natural que incita a geração de conhecimento com valor ontológico, o que faz com que a restauração da metafísica deva reivindicar a recuperação do prestígio filosófico do âmbito pré-teorético da vida cotidiana. A ontologia é o "reestabelecimento da direção natural do olhar (...) A ontologia (...) não prioriza a reflexividade. Adere diretamente à atitude natural" (Hartmann, 1965, p. 47). A atitude natural é valiosa para a ontologia uma vez que transmite a certeza de que o homem está rodeado por um mundo em vir-a-ser que dele independe. Não se trata de uma disposição empiricamente adquirida; mas uma assunção a priori (Hartmann, 1921, p. 96). Acredita-se, antes de tudo, na existência de coisas fora e independente do homem (recurso em alguma medida similar ao argumento naturalista de Strawson).

Distingue-se da atitude natural a atitude científica. Essa distinção consiste numa transformação do conteúdo da realidade avistada pelo realista ingênuo (a ciência busca pela substância por debaixo do cenário cambiante de nascimento e morte). Sem embargo, essa crítica não se estende à convicção na existência de uma realidade independente (idem, p. 97 e 98). As ciências (quer as ciências naturais, quer as ciências do espírito) legitimam a intentio recta da atitude natural. A transformação do conteúdo ocorre graças ao procedimento indutivo, peculiar à ciência, que redunda em generalizações; mas a primazia da intuitividade não é deixada de lado. Pelo contrário, a atitude científica baliza um tipo de visão mais aprimorada, a $\theta \varepsilon \omega \rho i ́ a$, que "penetra no pano de fundo (Hintergrund)" (Hartmann, 1965, p. 50).

A atitude científica prolonga e acentua a abertura do ente iniciada pela atitude natural; uma posição incomum no ambiente de debates fenomenológicos em que Hartmann estava de alguma forma inserido. A esse respeito, tome-se o caso de Scheler, que Hartmann tanto prezava (Hartmann, 1958b, p. 350 - 357). Para Scheler, as perspectivas naturais e científicas, em contraposição à fenomenológica, possuem caráter simbólico, acarretando numa gradativa perda de contato com as coisas mesmas. Decerto que a fenomenologia deve ser vista com um tipo de empirismo por privilegiar os fatos, distante de toda forma de racionalismo. Porém consiste num empirismo muito mais radical na medida em que a "filosofia fenomenológica é uma progressiva dessimbolização do mundo", capaz, então, de revelar o dado (Scheler, 1957a, p. 384). A visão natural prejudica a apreensão do dado - devido ao modo de abordagem inferencial que nos coloca diante de signos em relação (fogo inferido 
das chamas e fumaça sem ser dado diretamente, o "simbolismo da natureza") -, uma disposição que será intensificada com a visão científica, inserida num universo estritamente simbólico, cujo único objetivo é tornar possível a comunicação entre especialistas (símbolos da química, matemática, etc.). (Scheler, 1957b, p. 433 - 474). Para Hartmann, por outro lado, o método fenomenológico, ainda preso à reflexão, retarda o aumento da intuitividade quando se ocupa do fenômeno. A fenomenologia "não chegou nas coisas. Chegou somente no fenômeno das coisas" (Hartmann, 1965, p. 52). Constitui um pertinente esforço de ultrapassamento da reflexividade; mas ainda imperfeito. ${ }^{5}$ Embora Hartmann atribua particular importância ao método fenomenológico, por proporcionar acesso a determinados seres ideais (idem, p. 264 e 265), assim como às categorias (Hartmann, 1940, p. 589 - 591), ele censura muitos dos seus princípios ordenadores, como a promessa de restauração da ingenuidade pré-científica. ${ }^{6}$ Destarte, pode-se dizer que a ciência traz mais benefícios para a ontologia do que a fenomenologia, não obstante ser desprovida de recursos para explanar todos os estratos do ser.

A relação natural, a científica, e a ontológica com o mundo são, no fundo, uma e a mesma. Existe uma diferença somente no aspecto prático e na profundeza da penetração, mas não na atitude fundamental ante o campo inteiro dos objetos (Gegenstandsfeld), não na direção do conhecimento. A atitude natural está na científica e na ontológica. Mas como essa última é aquela que eleva o plano da consciência, pode-se dizer, com todo direito, de modo inverso: a atitude natural e a científica são já originariamente ontológicas. A ontologia encontra-se, portanto, não em parciais teorias filosóficas, mas toma seu ponto de partida imediatamente na vida e no trabalho da ciência, a atitude que lhe é adequada. Encontra-se por si-mesma no caminho da intentio recta (Hartmann, 1965, p. 48).

Quando Hartmann exalta o valor ontológico da ciência, ele não considera as propensões convencionalistas, promovidas pelo ficcionalismo e pragmatismo, que dirimem preocupações teoréticas e encerram a ciência a um modo de pensar calculador. Foi esse influxo que estimulou as críticas dirigidas pela fenomenologia à ciência (como no caso de Scheler); a ciência vista como um tipo de discurso artificial, destinado a uma comunidade de especialistas, que não guarda vínculo com o ente. Mas assumir uma posição fortemente crítica à ciência, em virtude de uma voga particular, faz com que se desconsidere que a ciência "dirigiu-se desde sempre ao ente enquanto ente” (idem, p. 217). E isso em razão da ciência não ser um puro conhecimento quantitativo.

Comecemos discorrendo sobre alguns aspectos da filosofia hartmanniana da

\footnotetext{
5 Retratar a fenomenologia como um método preparatório foi o principal motivo para Husserl afirmar, em cartas, que Hartmann pouco entendia a fenomenologia (e isso apesar de Husserl ter recepcionado de forma efusiva Grundzüge einer Metaphysik der Erkenntnis). Cf. Möckel, 2012, p. 110 - 114.

6 Essa é uma consideração intrigante, visto que Husserl entende a redução fenomenológica como uma reação à atitude natural. Sobre a compreensão heterodoxa que Hartmann possui da fenomenologia, cf. Spiegelberg, 1965, p. 374 e 375.
} 
matemática. Para Hartmann, os seres matemáticos são tipos de seres ideais que existem independentemente do pensamento. O legítimo conhecimento matemático é tornado possível pela intuição apreensiva. Quando se fala, por exemplo, sobre a soma dos ângulos do polígono, o juízo não está dirigido a um conceito, mas ao polígono mesmo; o conceito nada mais é do que o correlato representado do objeto. Isso não faz com que os seres matemáticos sejam, então, reais (como se fosse necessário intuir três coisas para se obter o número 3). Podemos dizer que o âmbito da matemática excede o pensamento e a realidade. Ainda assim, esses seres mantêm uma relação peculiar com a realidade, conferindo-lhe estrutura. A realidade acolhe parte das relações ideais dos seres matemáticos - números imaginários e espaços não euclidianos não estão contidos no mundo físico -, sendo condicionado por elas. As leis matemáticas são leis dos seres reais; fossem tão somente leis do pensamento, a natureza resistiria a todo tipo de cálculo. As leis matemáticas são intrínsecas à realidade e imprimem ordenação às leis da natureza; “o verdadeiramente maravilhoso nas leis naturais é, sem dúvida, sua estrutura matemática” (Hartmann, 1980, p. 402). No entanto, os processos naturais são irredutíveis às propriedades matemáticas. Hartmann manifesta aqui sua divergência com os "devotos investigadores do século XVII", herdeiros modernos do pitagorismo, que elegem a matemática como a "ciência do ‘divino' na natureza” (Hartmann, 1980, p. 406). O quantificável na natureza, além de tangenciar somente um estrato do ser real - o físico -, não é o mais originário.

Em primeiro lugar, a lógica, que pertence igualmente ao domínio do ser ideal, prescreve leis à matemática; “as leis lógicas são por natureza próprias do ser matemático e o domina como seu” (Hartmann, 1965, p. 276). Tome-se, por exemplo, uma lei permutativa $(a+b=b+a)$, inconcebível sem a suposição do princípio de identidade. Ademais, no campo da matemática aplicada das ciências naturais, ${ }^{7}$ as categorias de quantidade - uno e múltiplo; parte e todo; finito e infinito - dependem de outros conjuntos categoriais. Por certo que as ciências naturais foram movidas pelo anseio de montar um quadro de relações exatas dos fenômenos, encontrando na matemática o seu principal esteio; mas o estabelecimento de leis naturais supõe a interação com outras categorias. Por exemplo, para conceber uma "fórmula

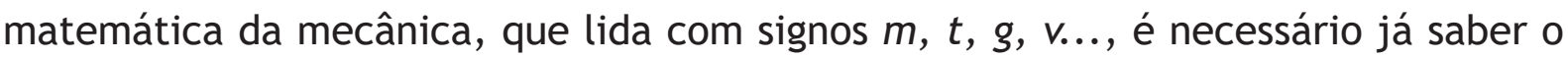
que são em geral massa, duração temporal, aceleração, velocidade”. Esse saber "não é um saber de quantidades, mas das relações em que se dá uma possível quantidade - ou, em fórmula categorial mais exata, os substratos e dimensões de uma possível quantidade" (idem, p. 219). As quantidades, quando cientificamente manuseadas, estão referenciadas a uma dimensão mais vasta de substratos categoriais, sendo preciso de antemão conhecê-los para que uma fórmula matemática possa ser

7 Sobre as diferenças entre matemática pura e aplicada em Hartmann, cf. Jacquette, 2011, p. 269 288. 
elaborada. Esses substratos são "antes de tudo o espaço e o tempo, e depois, não menos importantes, matéria, movimento, força, energia, processo causal e outros" (idem, p. 6 e 7).

A ciência assinala a existência das esferas de categorias, mesmo que ela não possa explicá-las; a visão científica não esgota o conhecimento do ente. ${ }^{8}$ Para tanto, é preciso lançar mão de métodos específicos (analítico-regressivo, dialético, sintético), posto que a atitude natural, e, consequentemente, científica, está voltada para o concreto, não diretamente para as categorias. As categorias estão junto às coisas, mas não podem ser imediatamente acessadas. Isso não significa dizer que algo como uma lei científica seja uma pura convenção que nada diz sobre o ente enquanto ente. Essas leis são reais, cumprindo, então, papel aproximativo.

\section{Considerações finais}

Tomando por base as apreciações de Hartmann sobre o caráter ontológico da ciência, há dois aspectos a serem considerados:

(i) Se Hartmann estiver certo, o mérito ontológico da ciência não está na fabricação de um outro tipo de regime discursivo, como quer Meillassoux, mas na capacidade de enfraquecimento do conhecimento guiado pela reflexividade, fonte do desvio correlativista. A ciência possui estatuto ontológico graças à capacidade de reabilitar e aperfeiçoar a intuitividade; antes de ser um tipo de discurso, ciência se caracteriza por ser uma atitude de viés ontológico que expande a intuição. Salvo melhor juízo, penso que esse entendimento evita um inconveniente de considerável gravidade se assumirmos que a linguagem das ciências é exclusivamente matemática. Pois nem todo discurso científico pode ser matematicamente formalizado (basta pensar em ciências que integram as Geisteswissenschaften).

(ii) Diferentemente de Meillassoux, Hartmann faz ver que a matemática não constitui a última fronteira ontológica. Quando a ciência deixa de ter como única tarefa a predição, convertendo-se num instrumento de relevância teórica para as incursões ontológicas da filosofia, ela ultrapassa o campo da matemática. Como vimos, os seres matemáticos são tipos de seres ideais, intrínsecos ao ente, mas que não gozam de caráter prioritário na escala ontológica. Hartmann não estima a ciência pela geração do discurso matemático, mas por sua aptidão de explicitar um campo diversificado de categorias (ainda que essa descrição esteja longe de ser conclusiva). Lembremonos, neste sentido, de como ele repreende a euforia dos cientistas modernos para

8 Conforme Torres, "a passagem para a determinação ontológica do real não cabe às ciências da natureza". O prosseguimento da interrogação ontológica requer expedientes filosóficos, embora não se trate aqui de uma oposição entre ciência e filosofia. "A filosofia não se constrói como um saber paralelo ao saber científico. Ela assume a tarefa, em Hartmann, de esclarecer de modo crítico os mesmos fenômenos sobre os quais a ciência constrói-se, enquanto ultrapassa os limites da ciência, até uma problematização última" (Torres, 2017, p. 133). 
com a matemática. Sendo assim, é de se perguntar se o "galileísmo" de Meillassoux não termina por encobrir êxitos ontológicos mais robustos das ciências.

\section{Referências}

Avé-Lallemant, E. (1975). „Die Antithese Freiburg-München in der Geschichte der Phänomenologie“. In: Kuhn, H., Avé-Lallemant, E. (Hrsg.). Die Münchener Phänomenologie. Den Haag: Martinus Nijhoff.

Bryant, L., Srnicek, N., Harman, G. (2010). “Towards a Speculative Philosophy”. In: The Speculative Turn: Continental Materialism and Realism. Melbourne: Re.press.

D’Anna, G. (2011). "Between Ontology and the Theory of Objects: Nicolai Hartmann and Hans Pichler". In: Poli, R., Scognamiglio, C., Tremblay, F. (eds.). The Philosophy of Nicolai Hartmann. Berlin/Boston: Walter de Gruyter.

Ferraris, M. (2014). Manifesto of New Realism. Tradução de Sarah De Sanctis. Albany: SUNY Press.

Harman, G. (2007). "Speculative Realism". In: Collapse. Philosophical Research and Development. Vol. IIII.

Hartmann, N. (1921). Grundzüge einer Metaphysik der Erkenntnis. Berlin/Leipzig: Walter de Gruyter.

- (1940). Der Aufbau der realen Welt. Grundriß der allgemeinen Kategorienlehre. Berlin: Walter de Gruyter.

. (1958a). „Alte und neue Ontologie“. In: Kleinere Schriften Band 3: Vom Neukantianismus zur Ontologie. Berlin: Walter de Gruyter.

(1958b). „Max Scheler“. In: Kleinere Schriften Band 3: Vom Neukantianismus zur Ontologie. Berlin: Walter de Gruyter.

- (1965). Zur Grundlegung der Ontologie. Berlin: Walter de Gruyter.

. (1980). PhilosophiederNatur:GrundrißderspeziellenKategorienlehre.

Berlin: Walter de Gruyter.

Heidegger, M. (2006). Sein und Zeit. Max Niemeyer: Tübingen.

Jacquete, D. (2011). “Hartmann's Philosophy of Mathematics". In: Poli, R., Scognamiglio, C., Tremblay, F. (eds.). The Philosophy of Nicolai Hartmann. Berlin/Boston: Walter de Gruyter.

Kluck, S. (2012). „Entwertung der Realität. Nicolai Hartmann als Kritiker der Ontologie Martin Heideggers“. In: Hartung, G., Wunsch, M., Strube, C. (Hrsg.). Von der Systemphilosophie zur systematischen Philosophie - Nicolai Hartmann. Berlin/ New York: Walter de Gruyter.

Meillassoux, Q. (2006). Après la finitude. Essai sur la nécessité de la contingence. Paris: Seuil.

Möckl, C. (2012). „Nicolai Hartmann - ein Phänomenologe? Zu den Termini Phänomen und Phänomenologie in Metaphysik der Erkenntnis“. In: Hartung, G., Wunsch, M., Strube, C. (Hrsg.). Von der Systemphilosophie zur systematischen Philosophie - 
Sobre o caráter ontológico da ciência: possíveis contribuições de Nicolai Hartmann ...

Nicolai Hartmann. Berlin/New York: Walter de Gruyter.

Peterson, K.R. (2016). "Scenes of Disagreement: Nicolai Hartmann between Phenomenological Ontology and Speculative Realism". In: Harding, B., Kelly, M. (eds.). Early Phenomenology: Metaphysics, Ethics and Philosophy of Religion. London: Bloomsbury.

. (2017). Nicolai Hartmann and Recent Realisms. Axiomathes, 27(2), pp. 161-174.

Scheler, M. (1957a) „Phänomenologie und Erkenntnistheorie“. In: Gesammelte Werke Band 10. Bern/München: Francke Verlag.

(1957b). „Lehre von den Drei Tatsachen“. In: Gesammelte Werke Band 10. Bern/München: Francke Verlag.

. (1973). „Die deutsche Philosophie der Gegenwart“. In: Gesammelte Werke Band 7. Bern/München: Francke Verlag.

Simons, P. (2013). “Metaphysics in Analytic Philosophy”. In: Beaney, M. (ed.). The Oxford Handbook of the History of Analytic Philosophy. Oxford: Oxford University Press.

Spiegelberg, H. (1965). The Phenomenological Movement. A Historical Introduction. Den Haag: Martinus Nijhoff.

Torres, J.V. (2017). Ciência \& realidade. G. Bachelard e N. Hartmann: por uma superação do realismo e do idealismo. São Paulo: Edições Loyola. 